University of New Hampshire

University of New Hampshire Scholars' Repository

8-6-2011

\title{
Fat mass limits lower-extremity relative strength and maximal walking performance in older women
}

\author{
Dain P. LaRoche \\ University of New Hampshire, Durham, dain.laroche@unh.edu \\ Rachel J. Kralian \\ University of New Hampshire, Durham \\ Erica D. Millett \\ University of New Hampshire, Durham
}

Follow this and additional works at: https://scholars.unh.edu/kinesiology_facpub

\section{Comments}

The publisher's final edited version of this article is available at: https://dx.doi.org/10.1016/j.jelekin.2011.07.006

\section{Recommended Citation}

D. P. LaRoche, Kralian, R.J. Millett, E.D. (2011) Fat mass limits lower-extremity relative strength and maximal walking performance in older women. Journal of Electromyography and Kinesiology. 21(5):754-761.

This Article is brought to you for free and open access by the Kinesiology at University of New Hampshire Scholars' Repository. It has been accepted for inclusion in Kinesiology Scholarship by an authorized administrator of University of New Hampshire Scholars' Repository. For more information, please contact Scholarly.Communication@unh.edu. 


\title{
Fat mass limits lower-extremity relative strength and maximal walking performance in older women
}

\author{
Dain P. LaRoche, Rachel J. Kralian, and Erica D. Millett \\ Department of Kinesiology, University of New Hampshire, Durham, NH
}

\begin{abstract}
The purpose of this study was to determine if excess fat negatively affects relative strength and walking gait performance in overweight, older women. Twenty five older women ( $65-80 \mathrm{yr})$ were separated into normal weight (BMI $<25 \mathrm{~kg} \mathrm{~m}^{-2}, \mathrm{n}=11$ ) and overweight groups (BMI $\geq 25$ $\mathrm{kg} \mathrm{m}^{-2}, \mathrm{n}=14$ ). Strength and rate of torque development (RTD) of the knee extensors and flexors, ankle plantarflexors and dorsiflexors were measured. Participants walked at standard and maximal speeds during which muscle activation, spatiotemporal and kinetic gait variables were measured. Relative to mass, overweight older women had $24 \%$ lower maximal torque and $38 \%$ lower RTD than normal weight women. Maximal walking speed was slower in overweight $\left(1.25 \pm 0.22 \mathrm{~m} \mathrm{~s}^{-1}\right.$ vs. $\left.1.54 \pm 0.25 \mathrm{~m} \mathrm{~s}^{-1}, \mathrm{P}=0.004\right)$ and was correlated to strength $(\mathrm{r}=0.53, \mathrm{P}<0.01)$ and fat mass $(\mathrm{r}$ $=-0.65, \mathrm{P}=0.001$ ). At maximal speed, overweight had $11 \%$ lower vertical ground reaction force relative to mass, $8 \%$ slower stride rate, $12 \%$ shorter strides, $13 \%$ longer foot-ground contact times, $21 \%$ longer double-limb support times, $65 \%$ greater knee extensor and $78 \%$ greater plantarflexor activation $(\mathrm{P}<0.05)$. Overweight, older women demonstrated altered gait and reduced walking performance related to poor relative strength and rate of torque development of lower-extremity muscles.
\end{abstract}

\section{Keywords}

MOBILITY LIMITATION; AGING; WEIGHT GAIN; SARCOPENIA; OBESITY; ACTIVITIES OF DAILY LIVING

\section{Introduction}

Older adults who have difficulty walking are at a twofold risk for both mortality and nursing home admission, making the maintenance of normal mobility an important health initiative [Guralnik et al., 1994]. In the aged, reduced leg strength and power have been associated with impaired stair climbing, gait speed, balance and chair rise ability [Bean et al., 2002]. In addition, excess body weight is a burgeoning concern that has also been shown to be a limiter of physical performance in this demographic [Sternfeld et al., 2002; Baumgartner et al., 2004; Vincent et al., 2010]. Research has shown that older adults with both muscle

(C) 2011 Elsevier Ltd. All rights reserved.

Corresponding Author: Dain P. LaRoche, Ph.D., Author Address: 124 Main Street, Durham, NH 03824, Author Phone: (603)-862-4859, Author Fax: (603)-862-0154, Dain.LaRoche@unh.edu.

Publisher's Disclaimer: This is a PDF file of an unedited manuscript that has been accepted for publication. As a service to our customers we are providing this early version of the manuscript. The manuscript will undergo copyediting, typesetting, and review of the resulting proof before it is published in its final citable form. Please note that during the production process errors may be discovered which could affect the content, and all legal disclaimers that apply to the journal pertain.

Conflict of interest statement

None declared. 
weakness and obesity have the slowest habitual gait speeds, greatest declines in walking speed over time, and greatest risk of developing mobility disability [Stenholm et al., 2009; Bouchard et al., 2010]. Currently, the biomechanical connection between excess body weight and altered gait has been studied more extensively in young adults than in old, and to the authors' knowledge, an integrated analysis of body composition, body mass-specific strength (relative strength), gait mechanics and mobility in older women has not been performed. It is particularly important to investigate the mechanisms of reduced mobility in older women who have lower strength, greater adiposity and a greater risk of mobility limitation than do men [Davison et al., 2002; Visser et al., 2005; Stenholm et al., 2007].

In younger individuals $(\bar{x}=39 \mathrm{yr})$, Spyropoulos and colleagues [1991] showed that the obese walked $33 \%$ slower and had wider step widths, shorter strides and slower stride rates than their non-obese counterparts. A study by Browning \& Kram indicated that obese individuals $(\overline{\mathrm{x}}=29 \mathrm{yr})$ produced $60 \%$ greater absolute vertical ground reaction force (vGRF) during stance, but similar vGRF relative to weight across most of the standardized speeds at which they walked [Browning et al., 2007]. This study also demonstrated that absolute knee extensor moments were as much as $51 \%$ greater in obese whereas knee extensor moments were not different when normalized to body mass. DeVita \& Hortobágyi showed in the obese $(\bar{x}=31 \mathrm{yr})$ that they had a 5\% shorter relative swing phase and 3\% longer relative stance phase compared to those of normal weight when walking at a standard speed [DeVita et al., 2003]. Lai et al. demonstrated that the obese $(\bar{x}=35 \mathrm{yr})$ chose slower self-selected gait speeds, had shorter strides, and increased double-limb support and stance time [Lai et al., 2008]. These authors theorized that the gait alterations seen in the obese were to moderate knee extensor moments and metabolic power [Lai et al., 2008].

Less attention has been dedicated to the study of gait in overweight and obese, older adults. Work by Messier has shown that obese, older adults with osteoarthritis $(\overline{\mathrm{x}}=69 \mathrm{yr})$ exhibited higher absolute vertical (28\%), anteroposterior (25-27\%) and mediolateral (25-38\%) GRFs as well as reduced stride length and slower walking velocity in comparison to non-obese, osteoarthritic subjects [Messier et al., 1996]. Also studying obese, older adults ( $\overline{\mathrm{x}}=68 \mathrm{yr}$ ), Ko et al. [2010] showed that they chose slower preferred walking speeds $\left(1.06 \pm 0.03 \mathrm{~m} \mathrm{~s}^{-1}\right.$ vs. $\left.1.20 \pm 0.03 \mathrm{~m} \mathrm{~s}^{-1}\right)$ and walked with a wider stride width $(0.12 \pm 0.004 \mathrm{~m}$ vs $0.10 \pm .003$ $\mathrm{m})$. These researchers also demonstrated that maximal gait speed declined with increasing body mass index (BMI) and that obese individuals had reduced ankle moments, as well as reduced generative and absorptive work at the ankle when walking maximally.

Currently the prevalence of overweight and obesity in the United States exceeds $65 \%$ of the adult population, and, there is an expected doubling of the number of senior citizens by year 2030 [Centers for Disease Control and Prevention, 2010]. We can consequently anticipate an increase in the number of older adults having mobility limitation and disability linked to excess body weight and should study how aging, strength loss and weight gain interact to affect functional mobility. Thus, the purpose of this study was to determine how excess fat affects relative strength and walking gait performance in overweight, older women. It was hypothesized that overweight, older women would have poor relative strength of the lowerextremity accompanied by reduced supportive forces relative to weight during walking and slower maximal walking speeds. Furthermore, it was hypothesized that overweight individuals would have reduced stride length, increased stride width, decreased single-limb and increased double-limb support time. 


\section{Methods}

\subsection{Participants}

Twenty-five independent, older women between the ages of $65-80 \mathrm{yr}$ who were able to walk unassisted were recruited (Table 1). The sample size was determined from previously published data to have adequate statistical power $(1-\beta=0.80)$ to detect significant differences between groups $(\mathrm{P}<0.05)$ in knee extensor maximal torque and rate of torque development [LaRoche, 2007]. The study was delimited to women because of their greater risk of mobility limitation and to eliminate sex as a confounding variable. Participants were excluded for having severe osteoporosis, severe osteoarthritis, neurological or cardiovascular disorders as reported by their primary care physicians in response to a health questionnaire. Women who met the criteria for participation, and who obtained consent from their primary care physicians, gave their own written, informed consent to participate in the research. The research protocol was approved for the use of human subjects by the university's Institutional Review Board.

\subsection{Experimental Design}

Upon arrival to the laboratory, height and body mass were measured, and using BMI, participants were assigned to normal weight (BMI $<25 \mathrm{~m} \mathrm{~kg}^{-2}, \mathrm{n}=11$ ) and overweight groups (BMI $\geq 25 \mathrm{~m} \mathrm{~kg}^{-2}, \mathrm{n}=14$ ). Body composition was further characterized through the use of whole body air-displacement plethysmography (Bod Pod, Life Measures, Inc. Concord, CA, USA) which has been demonstrated to closely agree with dual-energy X-ray absorptiometry estimates of body fat percentage $(r=0.95)$ [Sardinha et al., 1998]. Next, participants performed a Short Physical Performance Battery (SPPB) which included a standing balance test, a timed four-meter walk at the participant's habitual gait speed, and time to complete five chair rises [Guralnik et al., 1994]. This summary performance test has been shown to have good short-term reliability $(\mathrm{r} \approx 0.90)$ and sensitivity to change in health status [Ostir et al., 2002]. Current level of physical activity was determined using the Rapid Assessment of Physical Activity which has shown moderate agreement for estimates of energy expenditure $(\mathrm{r}=0.54)$ to a validated long form questionnaire and good sensitivity $(81 \%)$ to physical activity level [Topolski et al., 2006]. The questionnaire uses ordinal scores for aerobic activity ranging from 1 (rarely or never do any physical activities) to 7 ( $\geq$ 20 min day $^{-1}$ of vigorous physical activities, $\geq 3$ days week $^{-1}$ ) and for strength and flexibility, 0 (no participation) to 3 (participates in both exercises). Then, participants were habituated to the strength and walking protocols described below. Two to seven days later, participants returned to the laboratory and repeated the strength and treadmill walking tasks during which surface electromyograms were recorded for the knee extensors and ankle plantarflexors.

\subsection{Lower-extremity Strength and Rate of Torque Development}

Participants performed maximal voluntary isometric contractions (MVC) for the knee flexors (KF), knee extensors (KE), ankle plantarflexors (PF) and ankle dorsiflexors (DF) for each limb. KE and KF isometric contractions were performed at a knee angle of $105 \mathrm{deg}$ (full extension $=180 \mathrm{deg}$ ), ankle PF at an angle of $90 \mathrm{deg}$ and ankle DF at $100 \mathrm{deg}$. Participants were instructed to produce as much force, as quickly as possible, for two seconds following a visual cue. Two trials were completed for each of the four muscle groups and 30 seconds rest was provided between trials. All measurements were completed using a HUMAC Norm dynamometer (CSMI, Stoughton, MA, USA) integrated with a BIOPAC MP100 data acquisition system (Biopac Systems, Inc., Goleta, California, USA) that recorded joint torques from the analog output of the dynamometer. 
Torque from the load cell of the dynamometer was sampled at $1 \mathrm{kHz}$, and smoothed using the mean torque calculated over overlapping 50-sample $(50 \mathrm{~ms})$ epochs using BIOPAC AcqKnowledge software (Biopac Systems, Inc., Goleta, California, USA). Rate of joint torque development (RTD) was determined as the instantaneous rate of change in the torque versus time curve calculated over overlapping 50 -sample $(50 \mathrm{~ms})$ epochs (i.e. the difference in torque between sample 1 to sample 50 was divided by $0.05 \mathrm{~s}$, followed by sample $2-51$, $3-52$, etc.). The subsequent RTD data were simultaneously sampled at $1 \mathrm{kHz}$ along with torque and EMG. Maximal torque and RTD were recorded as the highest value produced over the two trials for each muscle group. The repeatability of determining maximal torque and RTD in the authors' laboratory is $r=0.95$ and $r=0.90$ respectively [LaRoche et al., 2008]. In addition to recording the absolute scores, relative strength and RTD were determined by normalizing the data to each participant's body mass. Right and left leg maximal torque and RTD scores were averaged and used for analysis.

\subsection{Muscle activation assessment}

Electromyograms (EMG) were recorded from the surface of the skin using preamplified surface electrodes ( $B \& L$ Engineering, Santa Ana, CA, USA). The electrodes had a fixed interelectrode distance of $35 \mathrm{~mm}$, a common mode rejection ratio of $95 \mathrm{~dB}$, amplified the signal at the surface of the skin $300 \times$, and bandwidth filtered the signal between $12-3,200$ $\mathrm{Hz}$. After the skin was cleaned and abraded to reduce skin impedance, the electrodes were placed superficial to the vastus lateralis muscle $10 \mathrm{~cm}$ proximal to the distal muscle-tendon junction and superficial to the medial gastrocnemius muscle $4 \mathrm{~cm}$ proximal to the distal muscle-tendon junction on the non-dominant leg. A ground electrode was placed over the proximal head of the fibula. The EMG signal was then imported to a personal computer via the BIOPAC MP100 data acquisition system where it was sampled at $1 \mathrm{kHz}$, band pass filtered $(30-500 \mathrm{~Hz})$ using the software's online digital filtering, full-wave rectified, and integrated every 20 samples using data acquisition software (BIOPAC AcqKnowledge). To evaluate the ability to quickly activate the muscle during the isometric contraction, onset EMG was determined by expressing the peak amplitude of the integrated EMG measured in the first $500 \mathrm{~ms}$ of contraction as a percentage of the peak EMG at MVC. To assess muscle activation during walking, the peak amplitude of the integrated EMG was recorded separately for weight acceptance and push-off phases and each was expressed as a percentage of the peak EMG measured during the MVC.

\subsection{Gait assessment}

Participants walked on a motorized, instrumented treadmill equipped with in-deck force plates (Gaitway II, Kistler Instrument Corp., Amherst, NY, USA) that recorded gait variables for each foot over ten sequential strides. The women walked at both a standard speed of $0.83 \mathrm{~m} \mathrm{~s}^{-1}$ and at a self-selected, maximal speed for approximately two minutes each. The analog force and center of pressure (COP) data from the treadmill's force plates were digitized using the treadmill's analog-digital board at $100 \mathrm{~Hz}$ using a personal computer and the treadmill's associated software and were recorded independently for both the right and left feet. The treadmill only provided the vertical component of the GRF and it was therefore not possible to measure the anteroposterior or mediolateral forces. For each step, an automated analysis identified the peak vGRF for both the first (weight acceptance) and second (push-off) force peaks (Figure 1). The weight acceptance rate was calculated as the slope of the force vs. time curve between $10-90 \%$ of the peak weight acceptance force and similarly the push-off rate was calculated as the slope of the force vs. time curve between $90-10 \%$ of the push-off peak force.

Using the contact time data obtained from each foot's force measurements, stride rate, footground contact time, single-limb support time, and double-limb support time were 
determined. Using COP data, stride length was measured as the distance from the initial COPx (anteroposterior) at foot contact of one foot to the next foot contact of the same foot. To account for the stationary nature of treadmill walking with respect to the ground, the software uses treadmill belt speed to assign sequentially more distant COPx as the person "makes forward progress" during the trial. Stride width was calculated as the average distance between the right and left foot COPy (mediolateral). For analysis, all gait measurements were averaged between the right and left legs and over the ten sequential strides.

\subsection{Statistical Analysis}

Means and standard deviations were determined for all measures. Differences between groups for descriptive and dependent measures were assessed using multivariate analysis of variance (SPSS v. 18, 233 S. Wacker Drive, Chicago, IL 60606, USA). Because height was different between the normal and overweight groups, a separate multivariate analysis of covariance was performed for the spatial and temporal gait parameters with height as a covariate. The strength of the relationships between dependent measures was tested using the Pearson product moment statistic. For all statistical tests significance was set at $\mathrm{P}<0.05$.

\section{Results}

Overweight were younger, heavier, shorter, and had higher BMIs and percent fat $(\mathrm{P}<0.01$, Table 1). Overweight, older women had similar lean mass as normal weight, but carried an additional $13.2 \mathrm{~kg}$ of fat mass. Overweight women had significantly lower overall SPPB scores with $17 \%$ slower habitual gait speed and $15 \%$ slower chair rise time (all $\mathrm{P}<0.05$ ). Additionally, fat mass was negatively correlated with chair rise time $(\mathrm{r}=0.55, \mathrm{P}=0.005)$ and maximal gait speed $(\mathrm{r}=-0.65, \mathrm{P}=0.003)$ but the correlation with habitual gait speed did not reach statistical significance $(r=-0.28, P=0.109)$.

When strength relative to body mass was assessed, overweight, older women demonstrated 17\% lower KE maximal torque, 20\% lower KF maximal torque, and $43 \%$ lower PF maximal torque than normal weight (Figure $2 \mathrm{~A}, \mathrm{P}<0.05$ ). Strength relative to body mass was correlated to fat mass for the KE $(r=-0.63, P=0.001), K F(r=-0.48, P=0.014)$, and PF ( $r$ $=-0.55, \mathrm{P}=0.005)$ but not for $\mathrm{DF}(\mathrm{r}=-0.31, \mathrm{P}=0.087)$. When absolute strength was compared, the groups had equivalent maximal torques for the KE, KF, and DF but overweight still showed 30\% lower maximal PF torque (36.4 \pm 15.4 vs. $51.6 \pm 13.5 \mathrm{Nm}, \mathrm{P}=$ 0.018). Similarly, normalizing strength to fat-free mass attenuated the difference in performance between groups for each joint action (Figure 2B). Relative to body weight, overweight had 42\% lower KE RTD, 39\% lower KF RTD, and 50\% lower PF RTD than normal weight (Figure 2C, $\mathrm{P}<0.05$ ). The differences between overweight and normal weight groups persisted even when maximal RTD was expressed in absolute terms (KE RTD, $407 \pm 205$ vs. $565 \pm 131 \mathrm{Nm} \mathrm{s}^{-1}$; KF RTD, $222 \pm 93$ vs. $292 \pm 63 \mathrm{Nm} \mathrm{s}^{-1}$; PF RTD, $159 \pm 83$ vs. $252 \pm 85 \mathrm{Nm} \mathrm{s}^{-1}$ respectively, all $\mathrm{P}<0.05$ ) and when normalized to fat-free mass (Figure 2D). The onset EMG measured during the first $500 \mathrm{~ms}$ of the isometric contraction was not different between normal and overweight groups for either the KE (96 \pm 30 vs. $80 \pm 24 \%$ peak EMG at MVC, $\mathrm{P}=0.195)$ or PF $(100 \pm 29$ vs. $98 \pm 44 \%$ peak EMG at MVC, $\mathrm{P}=0.935$ ), respectively.

At the standard walking speed of $0.83 \mathrm{~m} \mathrm{~s}^{-1}$ there were no differences between groups for any gait or muscle activation variable and therefore only the results of the maximal speed trial are reported next. During weight acceptance at the maximal speed, KE peak EMG was $52 \pm 23 \%$ peak EMG at MVC in overweight and $32 \pm 9 \%$ peak EMG at MVC in normal weight $(\mathrm{P}=0.029$, Figure 1A). The difference in KE peak EMG during push-off between overweight $(17 \pm 12 \%)$ and normal weight $(8 \pm 5 \%)$ approached statistical significance $(\mathrm{P}=$ 
0.057). Similarly, PF peak EMG was higher in overweight during weight acceptance (52 \pm $32 \%$ vs. $27 \pm 13 \%, \mathrm{P}=0.031)$ but not during push-off $(42 \pm 21 \%$ vs. $46 \pm 25 \%, \mathrm{P}=0.736)$. Correlational analysis demonstrated that there was a positive linear relationship between BMI and PF peak EMG during weight acceptance $(r=0.59, \mathrm{P}=0.003)$ but the correlation between BMI and muscle activation did not reach statistical significance for the KE during weight acceptance $(r=0.20, P=0.20)$, KE during push-off $(r=0.33, P=0.075)$, or PF during push-off $(\mathrm{r}=0.17, \mathrm{P}=0.24)$.

When walking at maximal speed, overweight experienced higher absolute vGRFs during weight acceptance ( $846 \pm 146$ vs. $730 \pm 74 \mathrm{~N}, \mathrm{P}=0.035)$ and push-off $(757 \pm 159$ vs. $613 \pm$ $58 \mathrm{~N}, \mathrm{P}=0.009$ ) than did normal weight (Figure 1B). This relationship between BMI and supportive force was reversed when the peak vGRF was expressed relative to body weight (Figure 1C) with overweight having an 11\% lower peak force during weight acceptance (Table 2, $\mathrm{P}=0.006)$. The push-off rate relative to weight was $18 \%$ lower in overweight $(\mathrm{P}=$ 0.026). At maximal speed, overweight demonstrated $8 \%$ slower stride rates, $12 \%$ shorter strides, $13 \%$ longer foot-ground contact times, and $21 \%$ longer double-limb support times (Table 2, $\mathrm{P}<0.05)$. With the exception of stride length $(\mathrm{P}=0.067)$, the differences in these gait parameters remained when height was used as a covariate.

Figure 3A demonstrates that maximal walking speeds were strongly associated with peak vGRFs and Figure 3B shows that KE strength was moderately correlated to the maximal walking speed. When examining the relationship between body composition and walking performance, lean body mass was not associated with maximal speed (Figure 3C) whereas fat mass was inversely correlated to speed (Figure 3D).

\section{Discussion}

This study supports the hypothesis that excess fat mass in overweight, older women is related to substantially reduced lower-extremity relative strength and RTD. In these women, maximal gait speed was slower despite greater absolute vGRF and activation of the lowerextremity antigravity muscles. Normalized, maximal vGRF were below that of those with normal body weight demonstrating that excess fat mass attenuates the ability to support the body in opposition to gravity. Overweight older women exhibited reduced stride length, stride rate, and, increased double-limb support and foot-ground contact times during maximal walking. Low relative strength and high fat mass were associated with slower maximal walking speeds.

\subsection{Body Composition and Physical Performance}

Traditionally, the loss of muscle mass (sarcopenia) has been purported to be the major cause of the decline in physical function seen with aging [Roubenoff, 2003] but an increasing number of studies demonstrate the deleterious effects of obesity in older age [Vincent et al., 2010]. In the current study, lean mass was not a distinguishing factor of physical performance in older women. On the contrary, fat mass was shown to limit walking performance, explaining $42 \%$ of the variance in maximal walking speed. Because there were negligible differences between the groups for absolute strength and strength per kilogram of fat-free mass, the authors speculate that the low relative strength, slower chair rise time and slower gait speed seen in the overweight were a consequence of higher fat mass. The significant correlations between fat mass and these performance variables support this opinion. What is concerning is that low relative strength was related to slower habitual and maximal walking speeds placing overweight, older adults at greater risk for mobility limitation. For example, a knee extensor torque threshold of approximately $1.5 \mathrm{Nm} \mathrm{kg}^{-1}$ (half of bilateral strength score) has been shown to differentiate between those at risk for impaired chair rise, gait speed, and stair ascent and descent [Ploutz-Snyder et al., 2002]. 
Using this benchmark, normal weight women in this study were slightly above this functional threshold $\left(1.53 \mathrm{Nm} \mathrm{kg}^{-1}\right)$ whereas overweight women fell below $\left(1.26 \mathrm{Nm} \mathrm{kg}^{-1}\right)$ with the consequence of reduced gait speed and increased chair rise time.

What cannot be simply explained by excess fat mass, is the large decrement in RTD in overweight older women that was not mitigated when expressed in absolute terms or when normalized to fat-free mass. It is likely that as a result of reduced relative strength and heavier limbs, movement speed and muscle shortening velocity are reduced in overweight, older adults. In this study, lower maximum weight acceptance and push-off rates were seen in overweight individuals that could have led to neuromuscular detraining over time. This is concerning as the rapid application of force has been shown to be more closely related to physical function and fall risk than strength [Bean et al., 2002; Perry et al., 2007]. While no differences were seen between groups in the ability to rapidly activate the muscle during an isometric contraction, more sensitive experiments that include the study of muscle physiology, composition, central and peripheral nervous function should be performed to explore the decreased muscular performance demonstrated by the overweight women in this study.

\subsection{Body Weight and Walking Gait}

Different gait in the overweight occurred concurrently with a $19 \%$ reduction in maximal walking speed. Despite walking at a slower speed, the peak absolute vGRFs during both weight acceptance and push-off were higher in those who were overweight. These data are in agreement with Browning \& Kram [2007] and Messier et al. [1996] who demonstrated that at standard speeds obese individuals generated higher peak vGRFs. This phenomenon reflects the greater forces between the foot and ground as a result of increased body mass, and assuming vGRF varies in proportion to the sum of the ankle, knee and hip extensor moments [Hof, 2000], is likely representative of the muscular force that must be produced to support body weight. Given that the absolute strength of lower-extremity muscles was comparable between groups, in those who are overweight, the supportive forces generated during walking represent a greater percentage of their lower-extremity strength. Additionally, higher absolute vGRF exhibited by the overweight likely place greater loads on joint structures and should be considered in the etiology of osteoarthritis. In fact, Messier et al. demonstrated the relationship between body weight and loading forces using an 18 month weight reduction program conducted in overweight and obese, osteoarthritic, older adults. In this study, for each $1 \mathrm{~kg}(\approx 10 \mathrm{~N})$ loss of body mass, compressive forces at the knee were reduced four fold $(40 \mathrm{~N})$ [Messier et al., 2005].

Greater levels of muscle activation of the KE and PF provide further evidence that overweight individuals use more effort to support body mass in opposition to gravity during walking. For the PF during weight acceptance, correlation demonstrated that as BMI increased there was a corresponding linear increase in muscle activation. Reduced muscular endurance may be exacerbated in those who are overweight by the reliance on highthreshold, type II motor units that are characterized by low fatigue resistance. Because of the inverse relationship between the force a muscle exerts and its ability to sustain repeated contractions, the high force (and greater muscle activation) required to support body mass in overweight older adults may result in early fatigue. For example, it has been shown that knee extensor weakness is a strong predictor of being unable to walk one kilometer [Lauretani et al., 2003].

When the vGRF were normalized to body mass, overweight older women demonstrated an $11 \%$ lower maximal force in comparison to normal weight. These data are in agreement with Lai et al. who also showed a $6 \%$ lower relative vGRF in younger obese adults in comparison to non-obese when walking at a self-selected speed [Lai et al., 2008]. The peak, normalized 
vGRF was closely tied to walking performance in this study as it is a prerequisite for the greater accelerations of body mass required at higher walking velocities. Because acceleration is proportional to the quotient of force and body mass, it followed that weak, overweight, older adults had slower habitual and maximal walking speeds.

During walking, speed can be modeled as the product of stride rate and stride length, both of which were lower in the overweight. Overweight individuals may have had greater leg mass, and with greater moments of inertia, resulted in a longer time to reposition the leg and correspondingly diminished maximal stride rates. It is likely that stride length was reduced in overweight subjects as a strategy to attenuate the force per step to match the relative strength of lower-extremity muscles such that early fatigue did not occur. Peak forces may have been reduced further in the overweight women by increasing the time spent simultaneously supporting the body with both legs and by applying force over a longer time period. These findings are in agreement with Ko et al. [2010] who demonstrated obese, older adults increase the duration of knee and ankle flexion during weight acceptance in an attempt to reduce loading forces. This approach, while limiting muscle force and metabolic work, as well as potentially delaying fatigue, reduces walking velocity and increases the risk for mobility limitation. For example, the habitual gait speed exhibited by the overweight group in the current study $\left(1.1 \mathrm{~m} \mathrm{~s}^{-1}\right)$ was slower than what is required to cross a street in the time allotted by the crossing signal $\left(1.2 \mathrm{~m} \mathrm{~s}^{-1}\right)$ and was close to the $<1.0 \mathrm{~ms}^{-1}$ cutpoint that has identified high risk for lower-extremity limitation, hospitalization, and death in older people [Cesari et al., 2005].

\subsection{Practical Applications}

As both excess body weight and low strength are modifiable, improvements in mobility may be made by either increasing lower-limb strength while keeping body mass constant or by decreasing body mass while maintaining strength. It has been demonstrated that weight loss as a result of diet and exercise can improve function in overweight and obese, older adults [Messier et al., 2004] but research suggests that only about $20 \%$ of individuals are able to lose $10 \%$ of body weight and maintain this weight loss for a year or more [Wing et al., 2005]. Additionally, weight loss may not be advocated for those classified as normal weight or overweight as these categories are associated with reduced risk for all-cause mortality in comparison to underweight and obese classifications [Corrada et al., 2006]. Thus, progressive strength and power training may be a more suitable means to modify both the ratio of strength to mass and functional performance in older adults [Steib et al., 2010]. As the largest deficiencies in strength and RTD were seen in the PF, and PF weakness has been identified as a factor related to a history of falls [LaRoche et al., 2010], training this muscle group may be especially important in the overweight.

\subsection{Limitations}

A limitation of the current study is that despite exclusion for severe osteoarthritis, no verification of the joint health of included participants was performed. Because the prevalence of osteoarthritis is higher in overweight individuals and osteoarthritis affects gait and mobility, it is possible that osteoarthritis could explain some of the differences in walking performance seen in this study [Messier et al., 1996; Stenholm et al., 2007]. Unexpectedly, the overweight group was five years younger than the normal weight group which may have blunted the detrimental effect of excess fat mass on strength and walking performance seen in this study. Possible explanations are that the age difference occurred due to chance, or, the younger, overweight participants responded to the study recruitment materials because they were beginning to experience difficulty in mobility and sought help, or, that the oldest, overweight individuals may not have participated because of greater loss of function. Although the two groups differed in height, the analysis of covariance indicated 
that height modestly affected stride length and did not significantly affect other gait and mobility variables.

\section{Conclusions}

Overweight, older women demonstrated reduced ability to support body weight during walking related to poor relative strength and rate of torque development of lower-extremity muscles. Overweight individuals appeared to adopt a gait pattern that attenuated maximal supportive forces by walking slower, taking shorter strides, sharing the work between legs, slowing the rate of force application, and lengthening the time that force was applied. Being overweight and having poor relative strength was associated with slower habitual and maximal walking speeds which may increase the risk for developing mobility limitation and disability. Interventions that serve to increase relative strength of lower extremity muscles through weight loss and/or strength gain, should therefore aid in the maintenance of mobility.

\section{Acknowledgments}

D.P. LaRoche was supported by the National Institute on Aging via NIH Grant L30 AG038028-01. The National Institutes of Health had no involvement in the study design, in the collection, analysis and interpretation of data; in the writing of the manuscript; or in the decision to submit the manuscript for publication. The authors would like to thank Anne M. Ronan, B.A., and Anthony R. Tagliaferro, Ph.D. for their assistance with body composition analysis.

\section{References}

Baumgartner RN, Wayne SJ, Waters DL, Janssen I, Gallagher D, Morley JE. Sarcopenic obesity predicts instrumental activities of daily living disability in the elderly. Obes Res. 2004; 12(12): 1995-2004. [PubMed: 15687401]

Bean JF, Kiely DK, Herman S, Leveille SG, Mizer K, Frontera WR, Fielding RA. The relationship between leg power and physical performance in mobility-limited older people. J Am Geriatr Soc. 2002; 50(3):461-467. [PubMed: 11943041]

Bouchard DR, Janssen I. Dynapenic-obesity and physical function in older adults. J Gerontol A Biol Sci Med Sci. 2010; 65(1):71-77. [PubMed: 19887536]

Browning RC, Kram R. Effects of obesity on the biomechanics of walking at different speeds. Med Sci Sports Exerc. 2007; 39(9):1632-1641. [PubMed: 17805097]

Centers for Disease Control and Prevention. National Center for Health Statistics. 2010. from http://www.cdc.gov/nchs/fastats/default.htm

Cesari M, Kritchevsky SB, Penninx BW, Nicklas BJ, Simonsick EM, Newman AB, Tylavsky FA, Brach JS, Satterfield S, Bauer DC, Visser M, Rubin SM, Harris TB, Pahor M. Prognostic value of usual gait speed in well-functioning older people-results from the Health, Aging and Body Composition Study. Journal of the American Geriatrics Society. 2005; 53(10):1675-1680. [PubMed: 16181165]

Corrada MM, Kawas CH, Mozaffar F, Paganini-Hill A. Association of body mass index and weight change with all-cause mortality in the elderly. Am J Epidemiol. 2006; 163(10):938-949. [PubMed: 16641311]

Davison KK, Ford ES, Cogswell ME, Dietz WH. Percentage of body fat and body mass index are associated with mobility limitations in people aged 70 and older from NHANES III. Journal of the American Geriatrics Society. 2002; 50(11):1802-1809. [PubMed: 12410898]

DeVita P, Hortobagyi T. Obesity is not associated with increased knee joint torque and power during level walking. J Biomech. 2003; 36(9):1355-1362. [PubMed: 12893044]

Guralnik JM, Simonsick EM, Ferrucci L, Glynn RJ, Berkman LF, Blazer DG, Scherr PA, Wallace RB. A short physical performance battery assessing lower extremity function: association with selfreported disability and prediction of mortality and nursing home admission. J Gerontol. 1994; 49(2):M85-M94. [PubMed: 8126356] 
Hof AL. On the interpretation of the support moment. Gait Posture. 2000; 12(3):196-199. [PubMed: 11154929]

Ko SU, Stenholm S, Ferrucci L. Characteristic gait patterns in older adults with obesity--Results from the Baltimore Longitudinal Study of Aging. J Biomech. 2010; 43(6):1104-1110. [PubMed: 20080238]

Lai PP, Leung AK, Li AN, Zhang M. Three-dimensional gait analysis of obese adults. Clin Biomech (Bristol, Avon). 2008; 23 Suppl 1:S2-S6.

LaRoche DP, Cremin KA, Greenleaf B, Croce RV. Rapid torque development in older female fallers and nonfallers: a comparison across lower-extremity muscles. J Electromyogr Kinesiol. 2010; 20(3):482-488. [PubMed: 19782579]

LaRoche DP, Knight CA, Dickie JL, Lussier MV, Roy SJ. Explosive Force and Fractionated Reaction Time in Elderly Low and High Active Women. Med Sci Sports Exerc. 2007; 39(9):1659-1665. [PubMed: 17805100]

LaRoche DP, Roy SJ, Knight CA, Dickie JL. Elderly Women Have Blunted Response to Resistance Training Despite Reduced Antagonist Coactivation. Med Sci Sports Exerc. 2008; 40:1660-1668. [PubMed: 18685524]

Lauretani F, Russo CR, Bandinelli S, Bartali B, Cavazzini C, Di lorio A, Corsi AM, Rantanen T, Guralnik JM, Ferrucci L. Age-associated changes in skeletal muscles and their effect on mobility: an operational diagnosis of sarcopenia. J Appl Physiol. 2003; 95(5):1851-1860. [PubMed: 14555665]

Messier SP, Ettinger WH, Doyle TE, Morgan T, James MK, O'Toole ML, Burns R. Obesity: Effects on gait in an osteoarthritic population. J Appl Biomech. 1996; 12:161-172.

Messier SP, Gutekunst DJ, Davis C, DeVita P. Weight loss reduces knee-joint loads in overweight and obese older adults with knee osteoarthritis. Arthritis Rheum. 2005; 52(7):2026-2032. [PubMed: 15986358]

Messier SP, Loeser RF, Miller GD, Morgan TM, Rejeski WJ, Sevick MA, Ettinger WH Jr, Pahor M, Williamson JD. Exercise and dietary weight loss in overweight and obese older adults with knee osteoarthritis: the Arthritis, Diet, and Activity Promotion Trial. Arthritis Rheum. 2004; 50(5): 1501-1510. [PubMed: 15146420]

Ostir GV, Volpato S, Fried LP, Chaves P, Guralnik JM. Reliability and sensitivity to change assessed for a summary measure of lower body function: results from the Women's Health and Aging Study. Journal of clinical epidemiology. 2002; 55(9):916-921. [PubMed: 12393080]

Perry MC, Carville SF, Smith IC, Rutherford OM, Newham DJ. Strength, power output and symmetry of leg muscles: effect of age and history of falling. Eur J Appl Physiol. 2007; 100(5):553-561. [PubMed: 16847676]

Ploutz-Snyder LL, Manini T, Ploutz-Snyder RJ, Wolf DA. Functionally relevant thresholds of quadriceps femoris strength. J Gerontol A Biol Sci Med Sci. 2002; 57(4):B144-B152. [PubMed: 11909879]

Roubenoff R. Sarcopenia: effects on body composition and function. J Gerontol A Biol Sci Med Sci. 2003; 58(11):1012-1017. [PubMed: 14630883]

Sardinha LB, Lohman TG, Teixeira PJ, Guedes DP, Going SB. Comparison of air displacement plethysmography with dual-energy X-ray absorptiometry and 3 field methods for estimating body composition in middle-aged men. Am J Clin Nutr. 1998; 68(4):786-793. [PubMed: 9771855]

Spyropoulos P, Pisciotta JC, Pavlou KN, Cairns MA, Simon SR. Biomechanical gait analysis in obese men. Arch Phys Med Rehabil. 1991; 72(13):1065-1070. [PubMed: 1741658]

Steib S, Schoene D, Pfeifer K. Dose-response relationship of resistance training in older adults: a meta-analysis. Medicine and science in sports and exercise. 2010; 42(5):902-914. [PubMed: 19996996]

Stenholm S, Alley D, Bandinelli S, Griswold ME, Koskinen S, Rantanen T, Guralnik JM, Ferrucci L. The effect of obesity combined with low muscle strength on decline in mobility in older persons: results from the InCHIANTI study. Int J Obes (Lond). 2009; 33(6):635-644. [PubMed: 19381155]

Stenholm S, Sainio P, Rantanen T, Alanen E, Koskinen S. Effect of co-morbidity on the association of high body mass index with walking limitation among men and women aged 55 years and older. Aging Clin Exp Res. 2007; 19(4):277-283. [PubMed: 17726357] 
Sternfeld B, Ngo L, Satariano WA, Tager IB. Associations of body composition with physical performance and self-reported functional limitation in elderly men and women. Am J Epidemiol. 2002; 156(2):110-121. [PubMed: 12117699]

Topolski TD, LoGerfo J, Patrick DL, Williams B, Walwick J, Patrick MB. The Rapid Assessment of Physical Activity (RAPA) among older adults. Prev Chronic Dis. 2006; 3(4):A118. [PubMed: 16978493]

Vincent HK, Vincent KR, Lamb KM. Obesity and mobility disability in the older adult. Obesity reviews : an official journal of the International Association for the Study of Obesity. 2010; 11(8): 568-579. [PubMed: 20059707]

Visser M, Goodpaster BH, Kritchevsky SB, Newman AB, Nevitt M, Rubin SM, Simonsick EM, Harris TB. Muscle mass, muscle strength, and muscle fat infiltration as predictors of incident mobility limitations in well-functioning older persons. J Gerontol A Biol Sci Med Sci. 2005; 60(3):324333. [PubMed: 15860469]

Wing RR, Phelan S. Long-term weight loss maintenance. Am J Clin Nutr. 2005; 82(1 Suppl):222S225S. [PubMed: 16002825]

\section{Biographies}

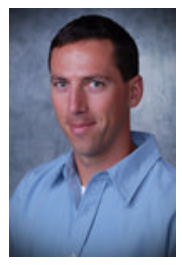

Dain LaRoche earned his Ph.D. from the Department of Exercise and Sport Science at the University of Utah, his M.S. from the University of Massachusetts - Amherst, and B.S. from the University of New Hampshire. He is currently an Assistant Professor of Exercise Science in the Department of Kinesiology at the University of New Hampshire, Durham, USA. His research interests include the role of physical activity in the preservation of neuromuscular function in aging, determinants of mobility and fall risk in the elderly, and the modifying role of body composition.

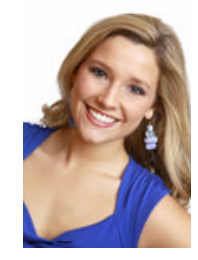

Erica Millett received her B.S. degree in Kinesiology: Exercise Science from the University of New Hampshire in 2010. At the University of New Hampshire she was awarded an undergraduate research fellowship to study how ankle muscle strength and passive muscle stiffness interact to affect ankle range of motion during walking in older adults. Erica is currently a group fitness instructor and the director of the female youth athlete program at The Next Level Training facility in Hampstead, New Hampshire, USA. She intends to pursue a career as a physician assistant.

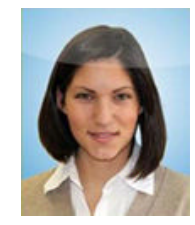

J Electromyogr Kinesiol. Author manuscript; available in PMC 2012 October 1. 
Rachel Kralian earned her B.S. degree in Kinesiology: Exercise Science at the University of New Hampshire in 2010. At the University of New Hampshire she was awarded an undergraduate research fellowship to study the role of visual acuity in the automaticity of walking in older adults. She is currently the Health Education Coordinator at Seven Hills Foundation, Worchester, Massachusetts, USA, an organization that promotes and encourages the empowerment of people with significant challenges. There she uses sciencebased research methods to develop and implement the organization's Health \& Wellness Strategy. 
A

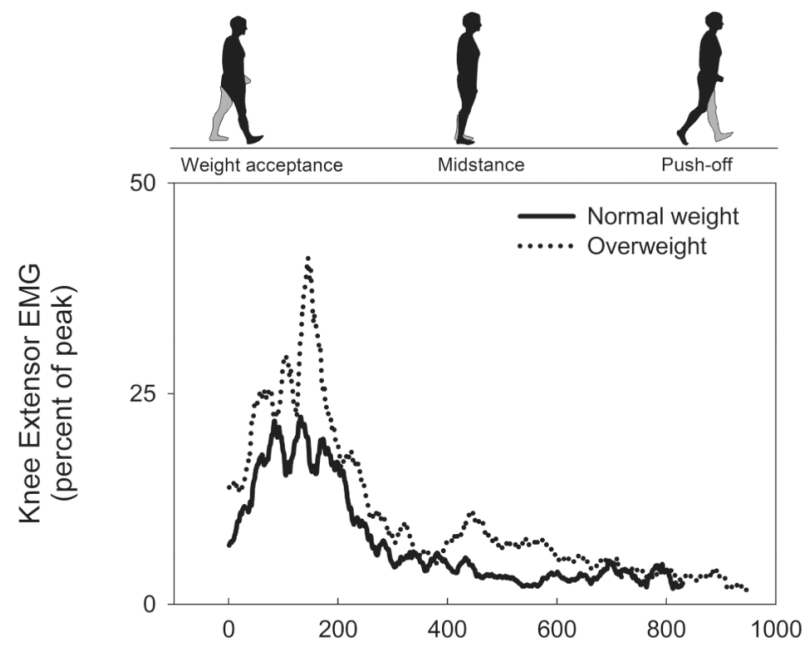

B

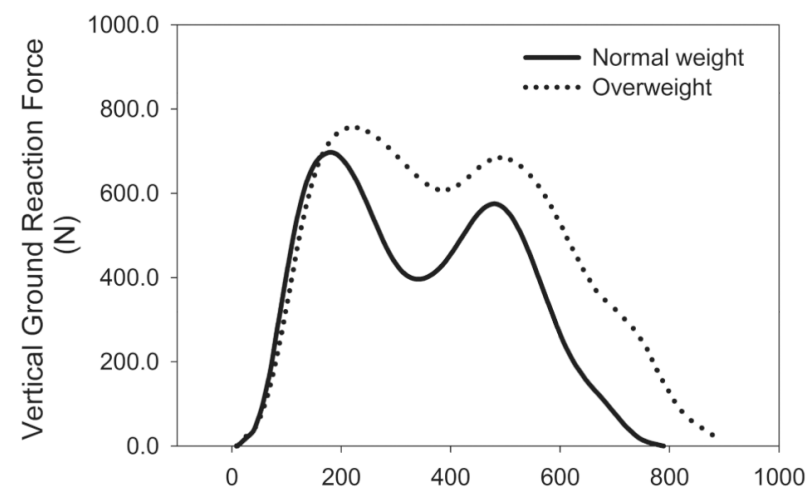

C

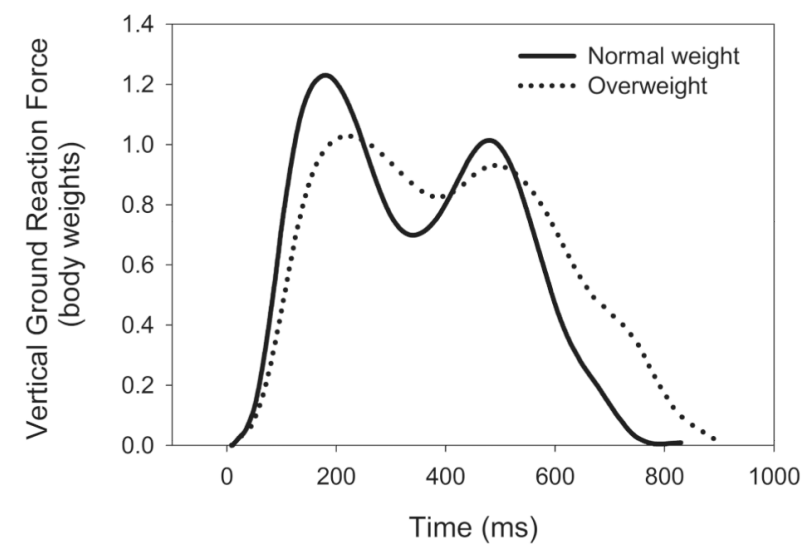

Figure 1.

Differences in muscle activation of the knee extensors (A), absolute vertical ground reaction force (B), and vertical ground reaction force relative to body weight (C) between normal weight and overweight groups during maximal walking. Solid line represents the mean response of those with normal body mass indices (BMI $<25 \mathrm{~kg} \mathrm{~m}^{-2}$ ) and dotted line represents the mean response of those with overweight body mass indices ( $\left.>25 \mathrm{~kg} \mathrm{~m}^{-2}\right)$. 
A

C
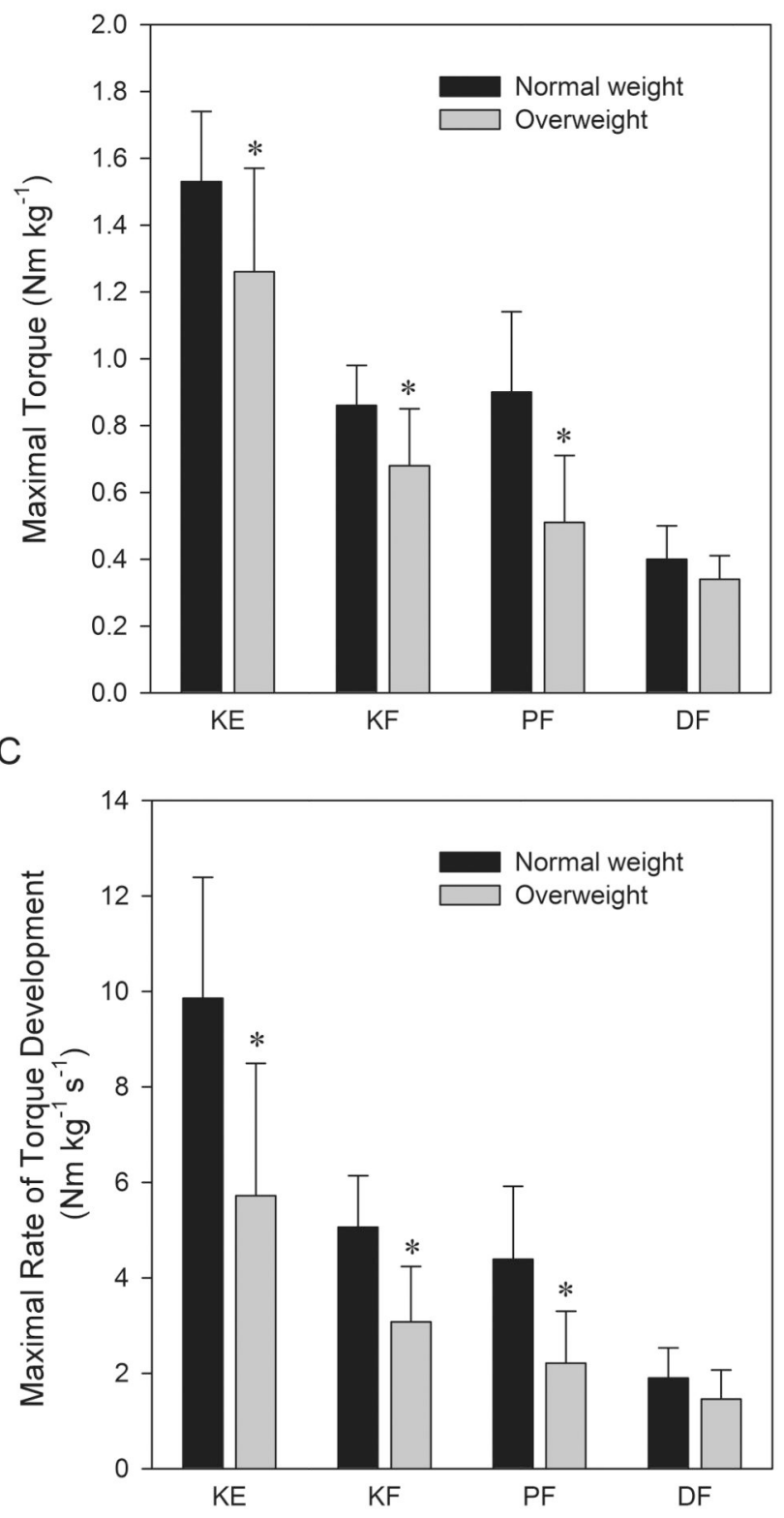

B
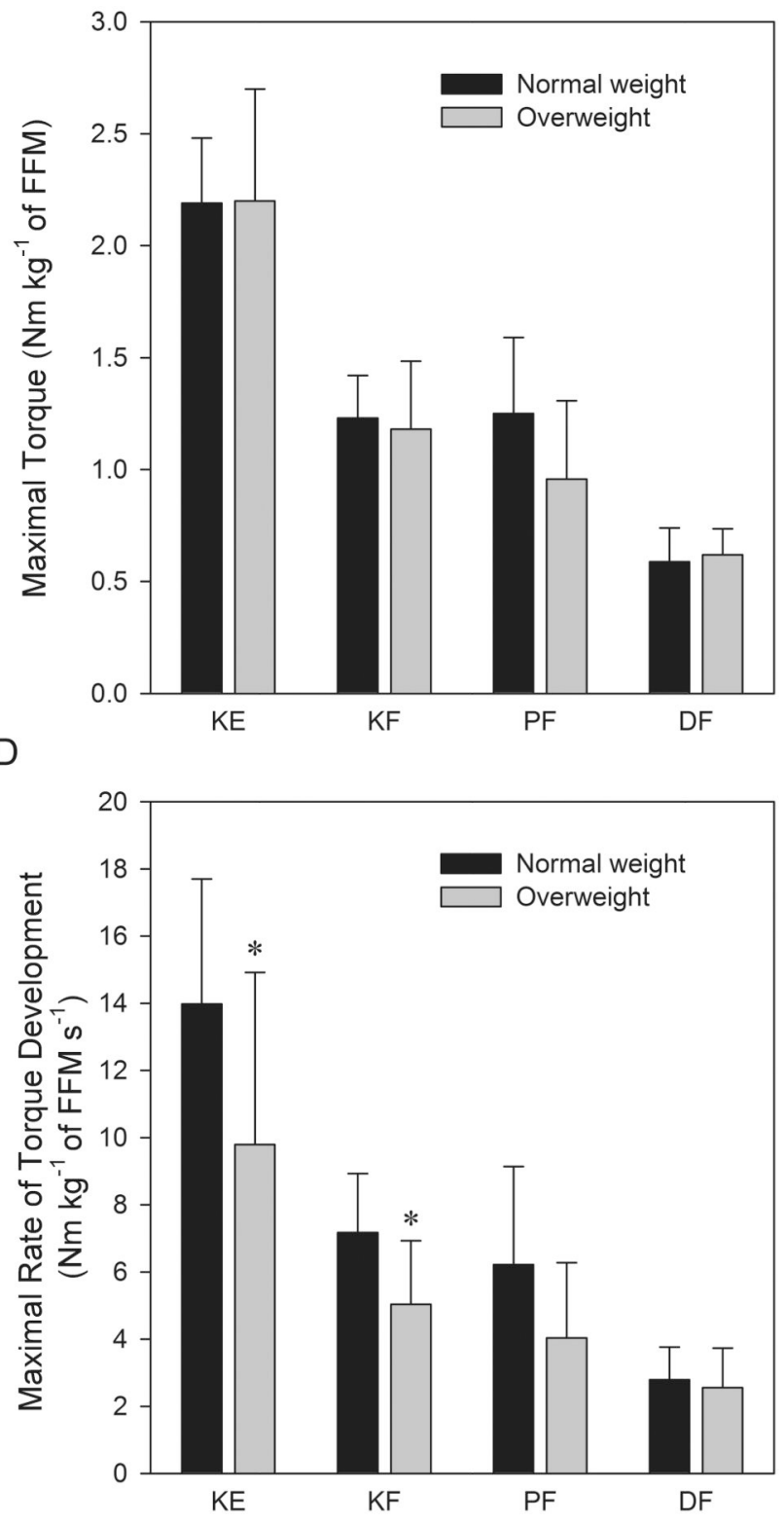

Figure 2.

Comparison of maximal torque relative to body mass (A) maximal rate of torque development relative to body mass (B) maximal torque relative to fat-free mass (FFM) (C) and maximal rate of torque development relative to fat-free mass (D) between those with normal and overweight body mass indices. Values are mean \pm SD. $*=$ difference between groups, P <0.05. KE, knee extensors; KF, knee flexors; PF, plantarflexors; DF, dorsiflexors. 
A

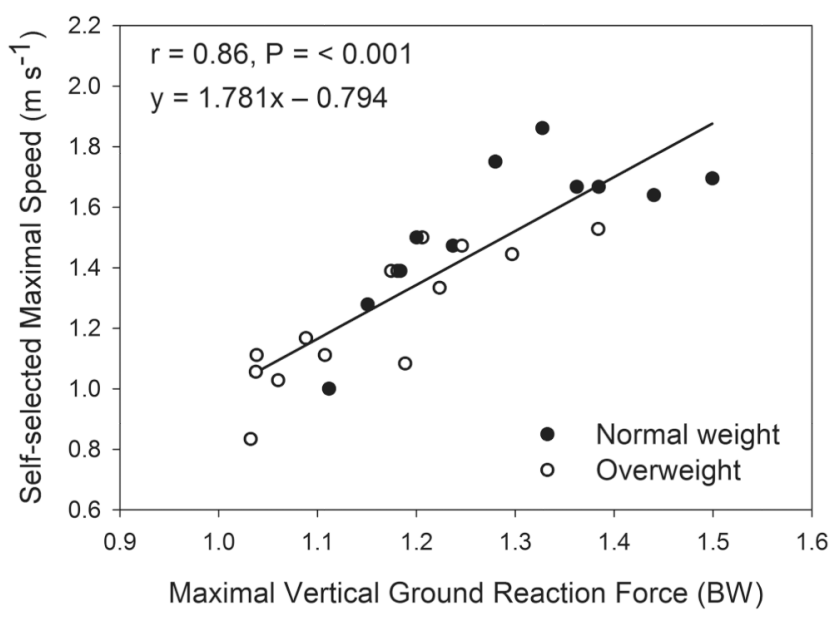

C

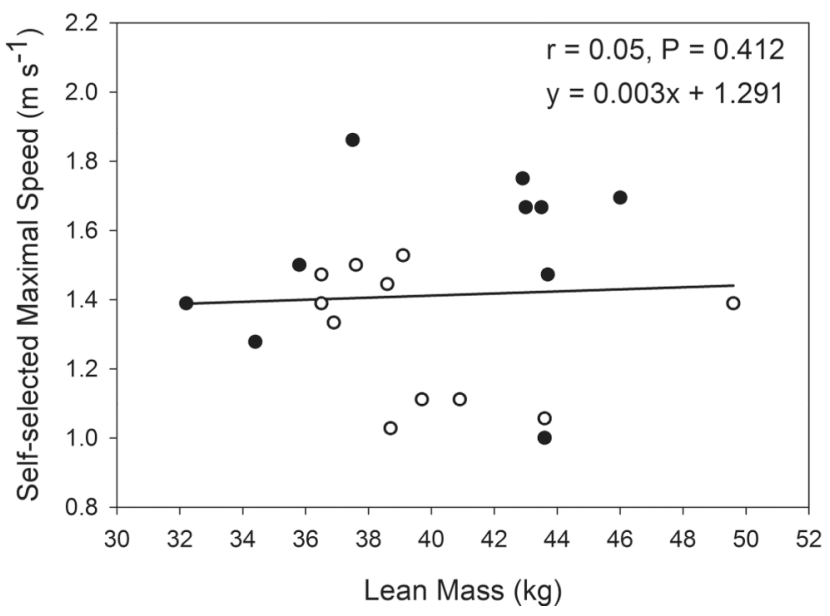

$\mathrm{B}$

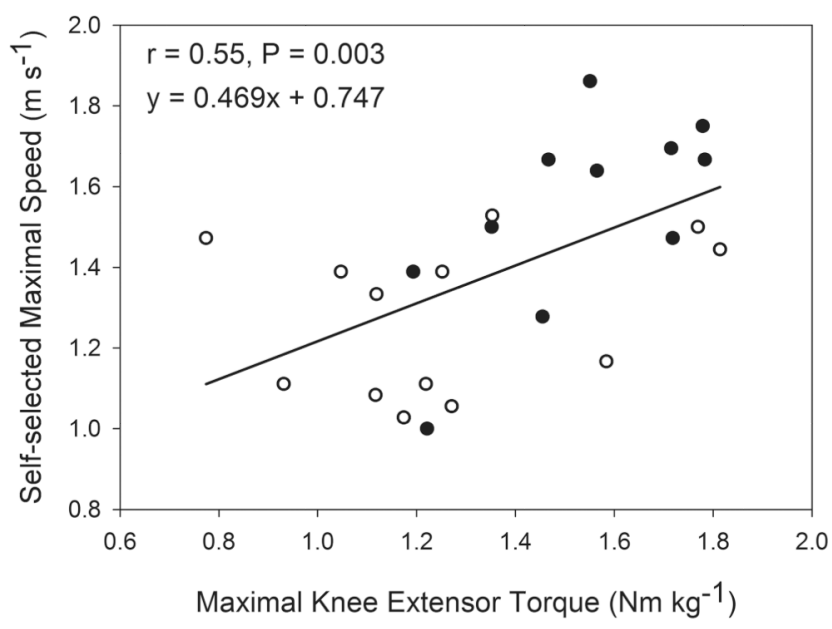

D

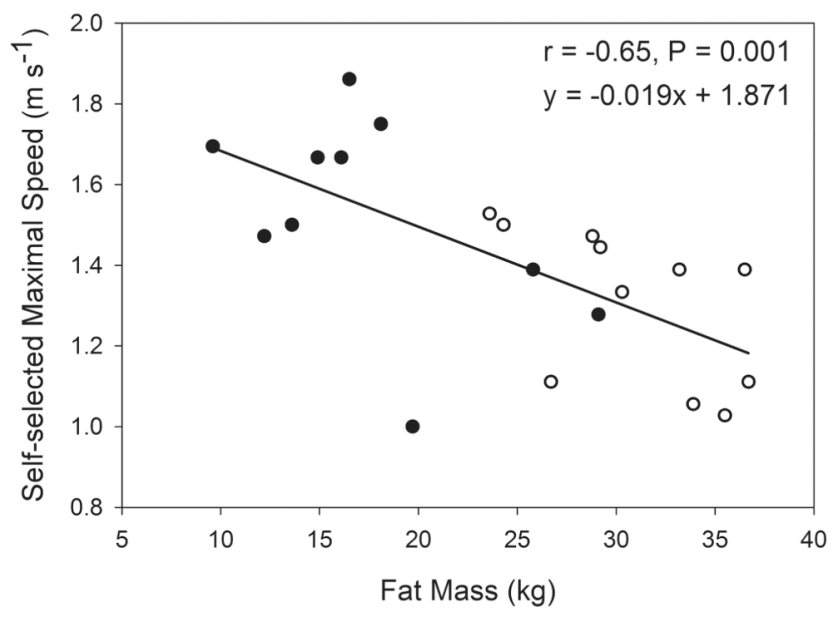

Figure 3.

Pearson product moment correlations associating self-selected, maximal walking speed with maximal vertical ground reaction force (A), maximal knee extensor torque (B), lean body mass (C) and body fat mass (D). Closed circles represent those with normal body mass indices (BMI $<25 \mathrm{~kg} \mathrm{~m}^{-2}$ ) and open circles overweight body mass indices $\left(>25 \mathrm{~kg} \mathrm{~m}^{-2}\right.$ ). $\mathrm{BW}=$ body weights. 
Table 1

Participant descriptive characteristics.

\begin{tabular}{lllc}
\hline & Normal weight & Overweight & P \\
\hline Age (yr) & $74.1 \pm 4.3(66-81)$ & $69.4 \pm 3.9(65-76)^{*}$ & 0.008 \\
Mass (kg) & $57.8 \pm 4.3(49.4-63.5)$ & $70.6 \pm 7.3(61.9-128)^{*}$ & $<0.001$ \\
Height (m) & $1.65 \pm 0.05(1.6-1.7)$ & $1.56 \pm 0.06(1.5-1.7) *$ & 0.002 \\
Body Mass Index $\left(\mathrm{kg} \mathrm{m}^{-2}\right)$ & $21.8 \pm 1.9(17.8-24.8)$ & $29.9 \pm 6.5(25.6-51.3) *$ & 0.001 \\
Percent Body Fat $(\%)$ & $30.1 \pm 9.0(17.3-45.8)$ & $43.5 \pm 3.6(37.7-48)^{*}$ & $<0.001$ \\
Fat Mass (kg) & $17.6 \pm 6.0(9.6-29.1)$ & $30.8 \pm 4.7(23.6-36.7) *$ & $<0.001$ \\
Lean Mass (kg) & $40.3 \pm 4.8(32.2-46.0)$ & $39.8 \pm 3.9(36.5-49.6)$ & 0.807 \\
Aerobic Physical Activity Score & $5.6 \pm 1.4(0-3)$ & $5.2 \pm 1.6(0-3)$ & 0.444 \\
Strength and Flexibility Activity Score & $2.3 \pm 1.2(3-7)$ & $1.6 \pm 1.3(3-7)$ & 0.205 \\
\hline & Lower-extremity Function & & \\
\hline SPPB Score & $11.5 \pm 0.7(10-12)$ & $10.6 \pm 1.2(8-12) *$ & 0.020 \\
Balance Score & $3.9 \pm 0.3(3-4)$ & $3.8 \pm 0.6(2-4)$ & 0.529 \\
Habitual Gait Speed (m s $\left.{ }^{-1}\right)$ & $1.31 \pm 0.25(0.95-1.90)$ & $1.11 \pm 0.19(0.85-1.48) *$ & 0.039 \\
Chair Rise Time (s) & $10.1 \pm 1.5(8.2-12.5)$ & $11.6 \pm 1.3(8.8-14.3) *$ & 0.013 \\
\hline
\end{tabular}

Values are mean $\pm \mathrm{SD}$ (range)

* difference between groups, $\mathrm{P}<0.05$

SPPB = Short Physical Performance Battery; the overall score is reported followed by the individual performances for each portion of the test . 
Table 2

Comparison of kinetic, temporal, and spatial gait parameters between normal and overweight groups at selfselected, maximal walking speed.

\begin{tabular}{llll}
\hline & Normal weight & Overweight & P \\
\hline Maximal Gait Speed $\left(\mathrm{m} \mathrm{s}^{-1}\right)$ & $1.54 \pm 0.25(1.00-1.86)$ & $1.25 \pm 0.22(1.03-1.53) *$ & 0.004 \\
Weight Acceptance Peak vGRF (BW) & $1.28 \pm 0.13(1.10-1.50)$ & $1.14 \pm 0.11(0.99-1.38) *$ & 0.006 \\
Push-off Peak vGRF (BW) & $1.08 \pm 0.07(0.92-1.23)$ & $1.03 \pm 0.07(0.93-1.21)$ & 0.134 \\
Weight Acceptance Rate (BW s $\left.{ }^{-1}\right)$ & $15.7 \pm 5.5(7.8-28.7)$ & $11.9 \pm 6.1(4.6-23.1)$ & 0.121 \\
Push-off Rate (BW s $\left.{ }^{-1}\right)$ & $-9.9 \pm 1.7(-6.8--12.7)$ & $-8.1 \pm 2.0(-5.7--11.4) *$ & 0.026 \\
Stride Rate (strides min $\left.{ }^{-1}\right)$ & $62.0 \pm 4.3(55.6-67.6)$ & $56.9 \pm 6.9(51.0-66.0) *$ & 0.049 \\
Stride Length (m) & $1.45 \pm 0.15(1.10-1.58)$ & $1.28 \pm 0.16(1.06-1.54) *$ & 0.015 \\
Stride Width (m) & $0.12 \pm 0.02(0.10-0.17)$ & $0.14 \pm 0.04(0.07-0.26)$ & 0.228 \\
Foot-ground Contact Time (s) & $0.62 \pm 0.06(0.56-0.73)$ & $0.70 \pm 0.08(0.60-0.78) *$ & 0.013 \\
Double-limb Support Time (s) & $0.14 \pm 0.03(0.11-0.19)$ & $0.17 \pm 0.03(0.13-0.22) *$ & 0.006 \\
Single-limb Support Time (s) & $0.35 \pm 0.02(0.31-0.38)$ & $0.35 \pm 0.03(0.29-0.39)$ & 0.756 \\
\hline
\end{tabular}

Values are mean $\pm \mathrm{SD}$ (range)

* difference between groups, $\mathrm{P}<0.05$

$\mathrm{vGRF}=$ vertical ground reaction force

$\mathrm{BW}=$ body weights 